\title{
IPTEKS PROSEDUR PERTANGGUNGJAWABAN BIAYA PERJALANAN DINAS PADA BIRO UMUM DAN PROTOKOL SEKRETARIAT DAERAH PROVINSI SULAWESI UTARA
}

\author{
Ferdinand Vikky Rompas ${ }^{1}$, Fanda D.P Rundengan ${ }^{2}$ \\ ${ }^{1,2}$ Jurusan Akuntansi, Fakultas Ekonomi dan Bisnis, Universitas Sam Ratulangi, Jl. Kampus Bahu, Kota \\ Manado, 95115, Indonesia \\ Email: rompasferdinand1@gmail.com
}

\begin{abstract}
The government must run the wheels of government honestly and cleanly and its neighbors must comply with the applicable laws and regulations. In managing finances the government must be able to account for every rupiah spent in carrying out government duties. The corruption cases of Official Travel have been many because of those who were not responsible. Regulations concerning Official Travel in the PMK Number 113 of 2012 concerning domestic official travel for State officials, civil servants and temporary employees. The purpose of this study is to find out whether the Accountability of Travel Agency Services at the General Bureau and Protocol of the Regional Secretariat of North Sulawesi Province is in accordance with the PMK Number 113 of 2012 concerning domestic official travel for State officials, civil servants, and the employee is not permanent or not. The results of the study show that the Accountability of Travel Agency Services at the General Bureau and Protocol of the Regional Secretariat of North Sulawesi Province is in accordance with the PMK Number 113 of 2012.
\end{abstract}

Keywords: government, accountability, official travel costs.

\section{PENDAHULUAN}

Dalam menjalankan roda pemerintahan, pemerintah sangat diharapkan mampu mensejahterakan masyarakat, yang berarti pemerintah harus menjalankan segala tugas, wewenang, dan kewajibannya sesuai dengan peraturan perudang-undangan yang berlaku dan tidak boleh melakukan penyimpangan agar roda pemerintahan itu dapat berjalan dengan baik. Transparency International melakukan survey Indeks Persepsi Korupsi pada 180 negara dan hasil survey tersebut menunjukan bahwa Inonesia berada pada peringkat 96 pada tahun 2017 . Indonesia memperoleh Skor sebesar tiga puluh tujuh dalam daftar indeks tersebut (www.kpk.go.id). Skor untuk Negara paling korupsi adalah 0 dan skor 100 untuk Negara yang bersih dari korupsi. Skor rata- rata Indeks Persepsi Korupsi secara global adalah 43 dan Skor untuk ASEAN adalah 41. Skor Indeks Persepi Korupsi di Indonesia berada di bawah rata- rata baik secara global maupun diantara Negara- Negara ASEAN yang menunjukan bahwa kasus korupsi di Indonesia masih banyak terjadi dan meprihatinkan.

Kasus korupsi yang terjadi dalam lingkungan pemerintahan Indonesia sangat banyak terjadi termasuk juga didalamnya korupsi terhadap dana perjalanan dinas. Maraknya kasuskasus korupsi perjalanan dinas yang terjadi memberikan peringatan bagi pemerintah untuk meningkatkan sistem pengawasan yang ketat agar terhindar dari tindakan korupsi yang merugikan Negara. Perjalanan Dinas diatur dalam PMK No 113 Tahun 2012 tentang perjalanan dinas dalam negeri bagi pejabat Negara, pegawai negeri, dan pegawai tidak tetap. Segala ketentuan telah diatur dalam peraturan tersebut. Tata kelola pemerintahan yang baik merupakan salah satu tuntutan masyarakat yang harus dipenuhi dimana salah satu pilar tata kelola tersebut adalah akuntabilitas (Sujarweni 2014:28). Akuntabilitas merupakan pertanggungjawaban yang harus diberikan oleh seseorang yang diberikan tugas kepada 
pemberi tugas. Tujuan dari penelitian ini adalah untuk mengetahui Bagaimana Pertanggungjawaban Biaya Perjalananan Dinas Pada Biro Umum Dan Protokol Sekretariat Daerah Provinsi Sulawesi Utara.

\section{TINJAUAN PUSTAKA}

Perjalanan Dinas. Perjalanan Dinas merupakan perjalanan yang dilakukan untuk kepentingan Negara dalam wilayah Republik Indonesia (PMK No 113 Tahun 2012).

Pejabat Negara. Pejabat Negara yaitu pimpinan dan anggota lembaga tertinggi/tinggi negara sebagaimana dimaksud dalam UUD 1945 dan Pejabat Negara lainnya yang ditentukan oleh Undang-Undang (UU RI No 5 Tahun 2014).

Pegawai Negeri. Pegawai Negeri adalah warga Negara Indonesia yang memiliki tugas dalam suatu jabatan dalam negeri atau tugas Negara lainnya yang di gaji sesuai dengan perundangundangan yang diangkat oleh pejabat berwenang dan telah memenuhi semua syarat yang telah ditentukan (PP RI No 11 Tahun 2017).

Pegawai Tidak Tetap. Pegawai Tidak Tetap yaitu pegawai yang bekerja dalam jangka waktu tertentu yang ditentukan untuk melakukan tugas- tugas pemerintahan dan pembangunan yang berupa teknis professional dan administrasi yang dibutuhkan organisasi.

Biaya Rill. Biaya Riil adalah biaya yang benar- benar terjadi yang didukung dengan bukti pengeluaran yag sah (PMK No 113 Tahun 2012).

Pihak Pembuat Komitmen (PPK). PPK adalah pejabat yang memiliki wewenang atas Pengguna Anggaran atau Kuasa anggaran yang mengambil tindakan dan keputusan atas kegiatan yang dapat menyebabkan pengeluaran atas beban APBN (PMK No 113 Tahun 2012).

Akuntabilitas Publik. Akuntabilitas Publik merupakan kewajiban pihak pemegang amanah untuk mempertanggungjawabkan, menyajikan, melaporkan, dan mengungkapkan semua kegiatan atau aktifitas yang menjadi tanggungjawabnya kepada pihak pemberi amanah yang berwenang untuk meminta pertanggungjawaban tersebut (Mardiasmo 2009:17).

\section{METODE DAN TEKNIK PENERAPAN IPTEKS}

\subsection{Metode Penerapan Ipteks}

Metode penerapan ipteks yang digunakan adalah menganalisis Pertanggungjawaban Biaya Perjalananan Dinas Pada Biro Umum Dan Protokol Setda Prov. Sulut adalah Berdasarkan PMK Nomor 113 Tahun 2012 tentang perjalanan dinas dalam negeri bagi pejabat Negara, pegawai negeri, dan pegawai tidak tetap.

\subsection{Teknik Penerapan Ipteks}

Teknik yang digunakan untuk menganalisis Pertanggungjawaban Biaya Perjalananan Dinas Pada Biro Umum Dan Protokol Setda Provinsi Sulut adalah dengan membandingkan PMK Nomor 113 Tahun 2012 tentang perjalanan dinas dalam negeri untuk pejabat Negara, pegawai negeri, dan pegawai tidak tetap dengan penerapannya pada Biro Umum Dan Protokol Setda Provinsi Sulut apakah sudah sesuai atau tidak.

\section{PEMBAHASAN}

\subsection{Gambaran Objek Penerapan Ipteks}

Biro Umum dan Protokol Sekretariat Daerah Provinsi Sulawesi Utara adalah Lembaga Pemerintahan Non Departemen yang bertanggungjawab langsung kepada Presiden yang mempunyai tugas untuk Merumuskan kebijakan bidang bidang pelayanan publik, penataan kelembagaan dan ketatalaksanaan, bidang pengolahan data/informasi elektronik, dan bidang pendayagunaan aparatur. Bidang usaha yang dijalankan oleh Biro Umum dan Protokol Sekretariat Provinsi Sulawesi Utara terdapat beberapa bagian, yaitu: 
1. Bagian Administrasi dan Protokol; Untuk melaksanakan urusan Tata Usaha Pimpinan, Acara dan Fasilitasi Pimpinan, Fasilitisasi Tamu dan Perjalanan Dinas Pimpinan dan tugas lain yang menjadi tanggungjawabnya.

2. Bagian Rumah Tangga; Untuk melaksanakan Rumah Tangga Gubernur, Rumah Tangga Wakil Gubernur, dan Rumah Tangga Sekretariat Daerah dan tugas lain yang diberikan oleh pimpinan.

3. Bagian Adminsitrasi Keuangan; Untuk melaksanakan Perencanaan dan Pelaporan Keuangan Sekretariat Daerah, Tata Usaha Keuangan, dan Tata Usaha Biro dan tugas lain yang diberikan oleh pimpinan.

\subsection{Pembahasan}

Ipteks ini akan membahas pertanggungjawaban biaya perjalanan dinas pada biro umum dan protocol dan membandingkannya dengan PMK No 113 Tahun 2012 tentang perjalanan dinas dalam negeri bagi pejabat Negara, pegawai negeri, dan pegawai tidak tetap Bab IX pasal 34 mengenai Pertanggungjawaban Biaya Perjalanan Dinas.

\section{Pertanggungjawaban Biaya Perjalanan Dinas Berdasarkan Peraturan Menteri Keuangan Nomor 113 Tahun 2012.}

1. Setelah Perjalanan Dinas dilaksanakan pelaksana SPD harus mempertanggungjawabkan pelaksanaan Perjalanan Dinasnya kepada pemberi tugas dan biaya Perjalanan Dinas kepada Pejabat Pemberi Komitmen paling lambat 5 hari kerja.

2. Pertanggungjawaban atas biaya Perjalanan Dinas Jabatan melampirkan dokumen berupa:

a. Surat Tugas yang sah dari atasan Pelaksana SPD;

b. SPD yang telah ditandatangani oleh PPK dan pejabat di tempat pelaksanaan Perjalanan Dinas atau pihak terkait yang menjadi Tempat Tujuan Perjalanan Dinas;

c. Tiket pesawat, retribusi, boarding pass, airport tax, dan bukti pembayaran moda transportasi lainnya;

d. Melampirkan Daftar Pengeluaran Riil yang sesuai dengan format sebagaimana tercantum dalam Lampiran 9.

e. Bukti pembayaran berupa kuitansi atau bukti pembayaran lainnya yang sah untuk sewa kendaraan dalam Kota yang dikeluarkan oleh badan usaha yang bergerak di bidang jasa penyewaan kendaraan; dan

f. Bukti pembayaran penginapan atau hotel.

3. Apabila bukti pembayaran penginapan dan transportasi tidak diperoleh maka dapat hanya menggunakan daftar pengeluaran rill.

4. PPK melakukan perhitungan dan merampung seluruh bukti pengeluaran biaya Perjalanan Dinas dan disampaikan kepada Bendahara Pengeluaran.

5. Pejabat Pembuat Komitmen berwenang untuk menilai kewajaran dan kesesuaian biayabiaya yang tercantum dalam daftar pengeluaran.

6. Pejabat Pembuat Komitmen mengesahkan bukti-bukti pengeluaran yang terjadi dan menyampaikan kepada Bendahara Pengeluaran sebagai pertanggungjawaban UP atau bukti pengesahan Surat Permintaan Membayar/Surat Permintaan Pencairan Dana LS Perjalanan Dinas

Pertanggungjawaban Biaya Perjalanan Dinas pada Biro Umum dan Protokol Sekretariat Daerah Provinsi Sulawesi Utara.

1. Pelaksana SPD mempertanggungjawabkan pelaksaan perjalanan dinas kepada Pejabat Pelaksana Teknis Kegiatan (PPTK) dengan menyerahkan dokumen-dokumen dan buktibukti traksaksi yang terjadi atas pelaksaan perjalanan dinas seperti, Surat Tugas, SPD, airport tax, bukti pembayaraan tiket pesawat, boarding pass, retribusii, bukti pembayaran moda transportasi lainnya yang sah, bukti pembayaran penginapan yang sah dan daftar pengeluaran rill. 
2. PPTK melakukan Perhitungan rampung seluruh buktii- bukti pengeluaran biaya atas pelaksanaan Perjalanan Dinas dan kemudian disampaikan kepada Bendahara Pengeluaran.

3. Pejabat Pelaksana Teknis Kegiatan (PPTK) melakukan penilaian terhadap kesesuaian dan kewajaran atas biaya-biaya yang terjadi yang dicantumkan dalam daftar pengeluaran.

4. PPTK mengesahkan bukti pengeluaran yang telah diperiksa dengan cara membubuhkan paraf pada cap penyerahan dan menyampaikan kepada Bendahara Pengeluaran sebagai pertanggungjawaban bukti pengesahann Surat Permintaan Membayar/Surat Permintaan Pencairaan Dana LS Perjalanan Dinas.

\section{KESIMPULAN DAN SARAN}

\subsection{Kesimpulan}

Berdasarkan pembahasaan diatas, proses pertanggungjawaban biaya perjalanan dinas pada Biro Umum dan Protokoll Sekretariat Daerah Provinsi Sulawesi Utara sudah baik karena telah sesuai dengan Peraturan Menteri Keuangan Nomor 113 Tahun 2012 karena setiap pegawai yang melaksanakan perjalanan dinas mempertanggungjawabkan pelaksanaan perjalanan dinas dengan menyerahkan dokumen-dokumen dan bukti-bukti transaksi yang sah yang akan diperiksa oleh PPTK (Pejabat Pelaksana Teknis Kegiatan) untuk mengukur kesesuaian dan kewajaran atas biaya- biaya yang terjadi sehingga pengeluaran yang terjadi atas perjalanan dinas bisa diawasi dan terhindar dari penyimpangan.

\subsection{Saran}

Saran yang penulis berikan kepada Biro Umumm dan Protol Sekretariat Daerah Provinsi Sulawesi Utara dalam hal Pertanggungjawaban Biaya Perjalanan Dinas yang telah sesuai dengan Peraturann Menteri Keuangan Nomor 113 Tahun 2012 dapat di pertahankan dan menjadi lebih baik untuk tahun-tahun selajutnya.

\section{DAFTAR PUSTAKA}

Biro Umum dan Protocol Sekretariat Daerah Provinsi Sulawesi Utara. 2014. Biro Umum. http ://biroumum.sulutprov.go.id/?open=page \&id=5. Diakses pada 8 November 2018.

Biro Umum dan Protokol Sekretariat Daerah Provinsi Sulawesi Utara. 2018. Pertanggungjawaban Perjalanan Dinas Dalam Negeri.

Inspektorat Jendral Kementerian Riset Teknologi dan Pendidikan Tinggi. 2015. Salinan

Peraturan Menteri Nomor 113 Tahun 2012.http://itjen.ristekdikti.go.id/wpcontent/uploads/2015/11/Peraturan-Menteri-Keuangan-NOMOR-13PMK.052012.pdf. Diunduh pada 27 November 2018.

Inspektorat Jendral Kementerian Riset Teknologi dan Pendidikan Tinggi. 2015. Salinan

Peraturan Pemerintah Republik Indonesia Nomor 11 Tahun 2017. http://itjen.ristekdi kti.go.id/wp-content/uploads/2015/11/SALINAN-PP-Nomor-11-Tahun-2017-PP-

Nomor-11-Tahun-2017.pdf. Diakses pada 27 November 2018.

Jaringan dan Informasi Hukum Kementerian Keuangan Indonesia. Salinan Peraturan Menteri Nomor 113 Tahun 2012. https://jdih.kemenkeu.go.id/\#/. https://jdih.kemenke u.go.id/fullText/2012/113 PMK.05 2012Per.htm. Diakses pada 27 November 2018.

Jaringan dan Informasi Hukum Kementerian Keuangan Indonesia. 2018 Pengertian Pejabat Negara. https://jdih.kemenkeu.go.id/fullText/2014/5TAHUN2014UU.HTM. Diakses pada 27 November 2018.

Jaringan dan Informasi Hukum Kementerian Keuangan Indonesia. 2018.Pengertian Pegawai Tidak Tetap. http://www.jdih.kemenkeu.go.id/fullText/2007/45 PMK.05 2007Per.htm \#. Diakses pada 27 November 2018. 
Jaringan dan Informasi Hukum Kementerian

Keuangan Indonesia. 2018.

Pengertian Lumsum. https://jdih.kemenkeu.go.id/fullText/2003/7 KMK.02 2003Kep htm. Diakses pada 27 November 2018.

Komisi Pemberantasan Korupsi. 2017. Indeks Persepi Korupsi Indonesia tahun 2017. https://www.kpk.go.id/id/berita/berita-kpk/229-indeks-persepsi-korupsi-2017skor-indonesia-di-angka-37. Diakses pada 27 November 2018.

Mahmudi. 2011. Akuntansi Sektor Publik. UII Press: Yogyakarta.

Mardiasmo. 2009. Akuntansi Sektor Publlik. Andi: Yogyakarta.

Sujarweni Wiratna. 2015. Akuntansi Desa. Pustaka Baru: Yogyakarta. 